\title{
Thyroid Cartilage Chondrosarcoma Review: Management and Prognosis of a Rare Tumor
}

\author{
Antonio Rodríguez-Valiente ${ }^{*}$, Amaya Roldán-Fidalgo1, Jose Ramón García-Berrocal1, \\ Isabel Salas², Beatriz Brea ${ }^{3}$ \\ ${ }^{1}$ Department of Otorhinolaryngology, University Hospital Puerta de Hierro Majadahonda, Madrid, Spain \\ ${ }^{2}$ Department of Pathology, University Hospital Puerta de Hierro Majadahonda, Madrid, Spain \\ ${ }^{3}$ Department of Neuroradiology, University Hospital Puerta de Hierro Majadahonda, Madrid, Spain \\ Email: arova777@gmail.com
}

Received 10 January 2014; revised 9 February 2014; accepted 8 March 2014

Copyright (C) 2014 by authors and Scientific Research Publishing Inc.

This work is licensed under the Creative Commons Attribution International License (CC BY).

http://creativecommons.org/licenses/by/4.0/

(c) (i) Open Access

\begin{abstract}
Objective: This article is a critical review of the literature concerning thyroid cartilage chondrosarcoma and is particularly focused on the management and prognosis of this rare entity. Study Design: A review of all the cases of thyroid cartilage chondrosarcoma reported in the literature up to January 2013. Methods: The search was carried out through the introduction of the MeSH terms: Chondrosarcoma, Laryngeal Cartilages, Thyroid Cartilage, Therapeutics. All the studies related to thyroid cartilage chondrosarcoma were selected together with a newly presented case. Results: A total of 47 cases have been described in the literature, and 35 of these include sufficient data for statistical analysis. The age of patients ranged from 40 to 77 years, with a male predilection (88.6\%). The main symptoms were neck mass and hoarseness. Grade I and II tumors were most frequent. A total of 13 cases described an extension of the tumor beyond the thyroid cartilage. The most common treatment was partial laryngectomy $(50 \%)$. All patients who died were male, with grade II or II-III tumor or associated sarcoma, had metastases and received radiotherapy in addition to total laryngectomy. Conclusion: Patient age and tumor size does not influence the prognosis. Tumor grade I and I-II have good prognoses, whereas the prognosis is unpredictable in tumors between grade II and III. Patients with associated sarcoma, or metastasis, have a worse prognosis. Partial laryngectomy is a good therapeutic option, although total laryngectomy is sometimes required in order to ensure complete resection.
\end{abstract}

\section{Keywords}

Chondrosarcoma; Laryngeal Cartilages; Thyroid Cartilage; Therapeutics

*Corresponding author.

How to cite this paper: Rodríguez-Valiente, A., et al. (2014) Thyroid Cartilage Chondrosarcoma Review: Management and Prognosis of a Rare Tumor. International Journal of Otolaryngology and Head \& Neck Surgery, 3, 57-65. 


\section{Introduction}

Chondrosarcoma represents $10 \%-20 \%$ of all primary malignant bone tumors, and is the second most common sarcoma of bone origin [1]-[3]. Chondrosarcoma of the head and neck region is a rare disease $(1 \%-12 \%$ of chondrosarcomas) [4] [5], representing $0.1 \%$ of all head and neck neoplasms [6]. It is generally accepted that the tumor mostly arises in bony tissue of the head and neck [4] [6]-[8]. Common primary sites in the head and neck region include the mandible, nasal cavity, paranasal sinuses and maxilla.

Chondrosarcoma is the most common laryngeal sarcoma [9] [10], and represents less than $1 \%$ of all laryngeal tumors [11]. Approximately 70\% - 80\% of laryngeal chondroid malignancies involve the cricoid [10]-[13], with the second most common site (9\% - 20\%) being the thyroid cartilage [12] [13]. Laryngeal chondrosarcoma typically originates in hyaline cartilage [14], and less frequently in elastic cartilage (arytenoid and epiglottis cartilages) [15] [16]. Ossification in the cricoid and thyroid cartilages begins in the third decade and increases with advancing age [17], and is attributed to the influence of mechanical stimuli produced by contraction of the laryngeal muscles [17] [18]. The epiglottis remains nonossified throughout life [15].

Chondrosarcoma of the larynx is a rare condition of still unknown pathogenesis. The classic theories suggest that there is abnormal ossification on laryngeal cartilages. Another theory suggests malignant degeneration during the long-term development of a benign tumor [19]-[21]. There are some precipitating factors such as multiple hereditary exostoses, Ollier's disease, Maffucci's syndrome, Paget's disease of bone, chondromyxoid fibroma, and previous irradiation [7].

The epidemiology is variable, from slight male predilection to male-to-female predominance ranging from 5:1 up to as high as 10:1 [22]. The incidence increases with age and is more frequent between the 4th and the 7th decades [23].

Lymph node and distant metastasis are relatively low at 5.6\% and 6.7\%, respectively [24].

Some reports suggest a correlation between age, tumor size, and malignancy [25]-[27]. There are various histological patterns ranging from benign chondroid tumor to undifferentiated neoplasm [22]. Evans, et al. classified chondrosarcomas into grade I to grade III [28], whereas Koch, et al. classified them into high grade and low grade [6]. There are five histological types: conventional, clear cell (also known as malignant chondroblastoma), myxoid, mesenchymal (also called aggressive variant) and dedifferentiated (chondrosarcoma with additional malignant mesenchymal component).

Dedifferentiated chondrosarcomas have rapid growth [14] with an extremely poor prognosis [29] [30], and present imaging features very similar to well-differentiated types. Approximately $70 \%$ of patients manifest a pulmonary metastasis [31].

The symptoms depend on the location of the mass and include dyspnea, dysphagia and hoarseness. Tumors involving the thyroid cartilage are likely to produce a painless neck mass [32].

In the diagnosis, the most helpful computed tomography (CT) scan finding is coarse or stippled calcification within the tumor [32]. Magnetic resonance (MR) imaging can also show lesions within the larynx and has the potential advantage of superior contrast resolution of the tumor and contiguous tissues as well as the ability to capture images in multiple planes [33]. Biopsy by direct laryngoscopy is difficult due to the characteristic hardness and resistance of these tumors to grasping with cupped or biting laryngeal forceps [15]. The histological diagnosis of chondrosarcoma may sometimes be difficult.

The most important aspect in treatment is to ensure an adequate histological safety margin as residual disease is known to be an important cause of recurrence.

There are approximately 250 cases of cartilaginous tumors of the larynx which have been reported and discussed by various authors [15]. However we did not find any review that encompassed all thyroid cartilage chondrosarcomas. The aim of the present study was to update the management and prognosis of this rare entity and to present a new case.

\section{Materials and Methods}

A review was performed of all the cases of thyroid cartilage chondrosarcoma reported in the literature up to January 2013.

\subsection{Search Strategy}

The search was carried out through the introduction of the MeSH terms: "Chondrosarcoma”, "Laryngeal Carti- 
lages”, “Thyroid Cartilage”, “Therapeutics”.

First, a search was performed in clinical practice guideline databases (National Guideline Clearinghouse, Guidelines Finder NHS, CMA Infobase), however no references were found. Therefore a search of systematic reviews (Clinical Evidence, The Cochrane Library, DARE) was carried out, again without results. Finally, a review of original articles in PubMed was undertaken together with articles identified during this search process in order to add additional references.

\subsection{Selection Criteria}

Once all the abstracts were obtained, the studies related to thyroid cartilage chondrosarcoma were selected. Articles not directly related to laryngeal chondrosarcoma were discarded.

\subsection{Case Report}

A 63-year-old man came to the emergency department complaining of an anterior cervical mass of 3 months evolution. The patient reported discomfort on swallowing and the sensation of a foreign body in the pharynx. The oropharyngeal examination and the fibroscopy were normal. The physical examination revealed a painless, hard, rounded cervical lesion, measuring $1.5 \mathrm{~cm}$ in diameter, which moved on swallowing and was adhered to the deep planes, in the left cervical ganglion level III.

The CT scan showed an expansive mass of $2.3 \mathrm{~cm}$ in the posterior area of the left thyroid cartilage lamina with inflation and cortical breakage (Figure 1). Calcific foci with a popcorn-like appearance suggested a chondral origin. The MR showed a lesion indicating a low degree chondroma or chondrosarcoma of the left thyroid cartilage lamina (Figure 2). The patient underwent partial left laryngectomy. Histological examination
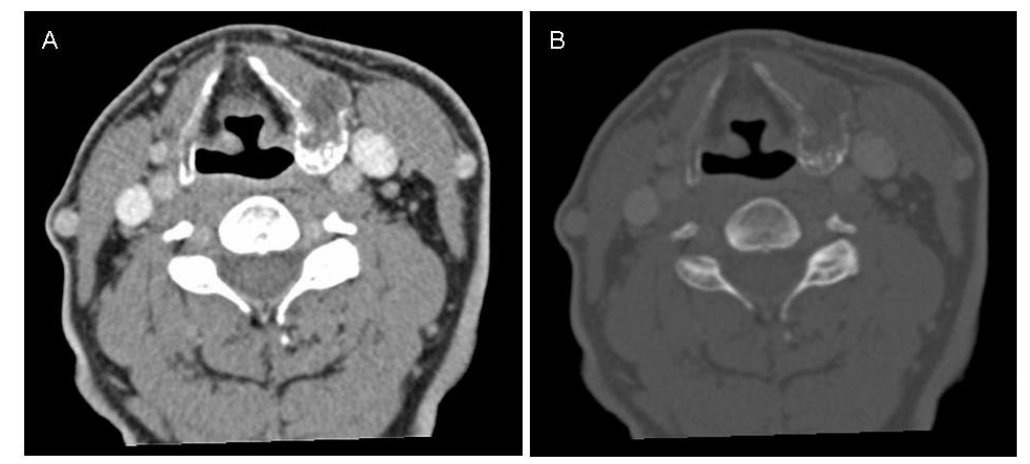

Figure 1. (A) CT axial soft tissue window; (B) CT axial bone window. Expansive mass in left cartilage thyroid lamina with chondroid calcification.
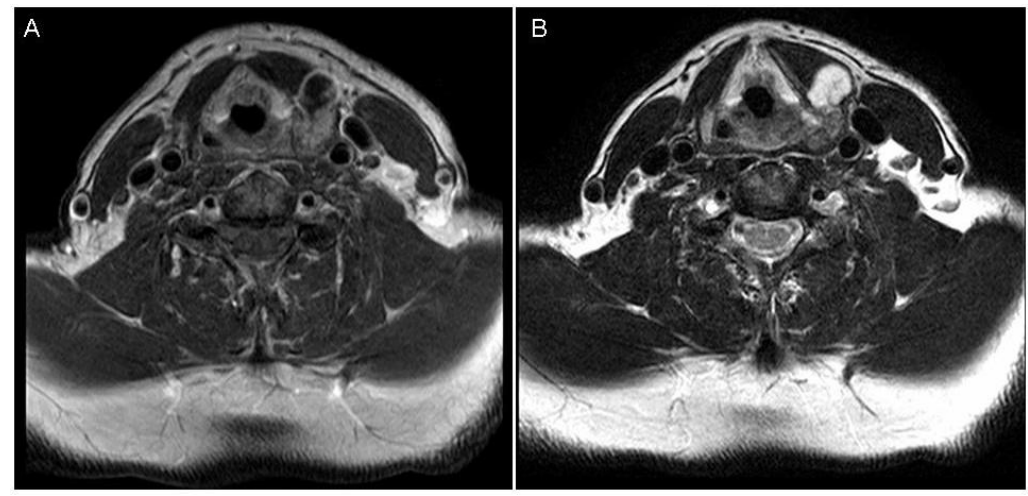

Figure 2. (A) MR axial T1 weigthed imaging after gadolium administration. Well defined mass in the left lamina with heterogeneous enhancement; (B) MR axial T2 weigthed imaging. The mass presents a hyperintense signal. This finding is very suggestive of chondroid matrix (mucopolysaccharides). 
of the surgical specimen confirmed the diagnosis of grade II chondrosarcoma with cellular pleomorphism and atypia, with a maximum diameter of $1.8 \mathrm{~cm}$, located on ossified thyroid cartilage. The lesion infiltrated the bone surface and prelaryngeal muscles. Areas of necrosis were identified within the tumor. Surgical margins showed no tumor infiltration (Figure 3).

Follow-up evaluations up to the present (51 months) have revealed no clinical signs of recurrent tumor or metastases.

\subsection{Statistical Analysis}

Data were analyzed using Statistical Package for Social Science (SPSS) version 15.0. Statistics procedures were established according to the recommendations of a professional statistician. The ANOVA test, three-way ANOVA, and the Turkey test for multiple comparisons were used for statistical analyses of the measured data. Descriptive statistics mean, median, and standard deviation (SD) were calculated in each group. The comparison between variables was evaluated by the $\chi^{2}$ test. All $\mathrm{p}$ values were two-sided and values of 0.05 or less were considered to indicate statistical significance.

\section{Results}

A total of 47 cases reporting thyroid chondrosarcoma were found in the literature, including the present case. Only 35 cases provided sufficient data for statistical analysis (Table 1).

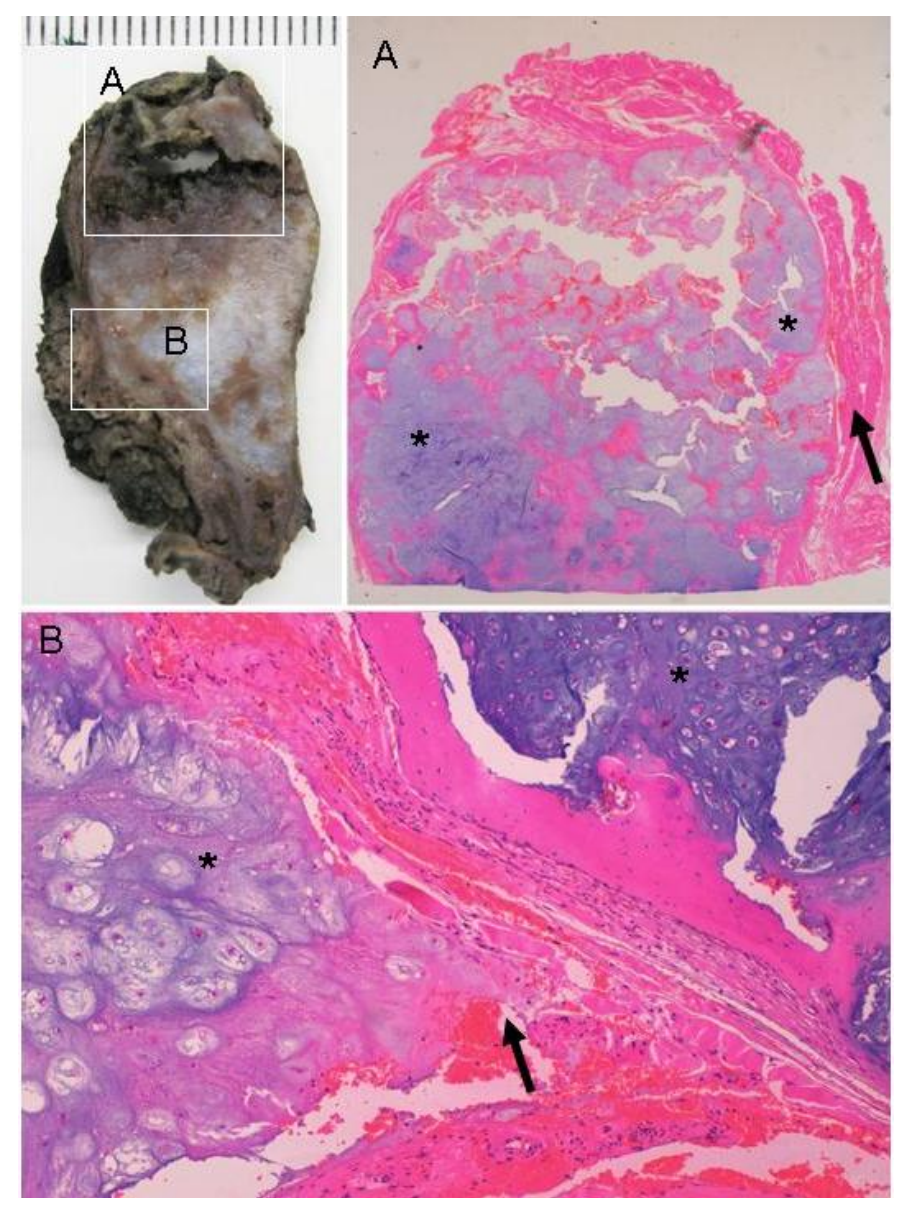

Figure 3. Histological sections of hematoxylin and eosin stain thyroid cartilage confirmed the diagnosis of grade II chondrosarcoma with cellular pleomorphism and atypia (asterisk), with a maximum diameter of $1.8 \mathrm{~cm}$, located on ossified thyroid cartilage. The lesion infiltrated the bone surface and prelaryngeal muscles (black arrow). 
Table 1. Description of the different studies reporting thyroid cartilage chondrosarcoma.

\begin{tabular}{|c|c|c|c|c|c|c|c|}
\hline References & $\begin{array}{l}\text { Age/ } \\
\text { Gender }\end{array}$ & $\begin{array}{l}\text { Symptoms } \\
\text { (duration) }\end{array}$ & $\begin{array}{l}\text { Extension } \\
\text { (metastasis) }\end{array}$ & Size (mm) & Pathology & Treatment & $\begin{array}{l}\text { Follow-up } \\
\text { (months) }\end{array}$ \\
\hline Busuttil, et al. (1978) [20] & $45 \mathrm{M}$ & Neck mass (9 y) & & $70 \times 55 \times 55(\mathrm{P})$ & Low grade & PL & NED (36) \\
\hline Gorenstein, et al. (1980) [9] & $55 \mathrm{M}$ & Dysphagia (6 mo) & & & Unknown & PL & NED (132) \\
\hline Gorenstein, et al. (1980) [9] & $73 \mathrm{~F}$ & Dysphagia (4 mo) & & & Unknown & PL & NED (120) \\
\hline Ferlito, et al. (1984) [10] & $74 \mathrm{M}$ & $\begin{array}{l}\text { Hoarseness (mo), } \\
\text { Dyspnea (we) }\end{array}$ & (Lung) & & Grade II & $\mathrm{TL}+\mathrm{RT}$ & DOD (2) \\
\hline Ferlito, et al. (1984) [10] & $50 \mathrm{~F} \mathrm{I}$ & Respiratory distress & Recurrence & $20(\mathrm{PE})$ & Grade I & PL-TL & NED (60) \\
\hline Finn, et al. (1984) [38] & $44 \mathrm{M}$ & Neck mass (14 yr) & & & Grade I & PL & NED (24) \\
\hline $\begin{array}{l}\text { Van Holsbeeck, } \\
\text { et al. (1985) [39] }\end{array}$ & $69 \mathrm{M}$ & $\begin{array}{l}\text { Hoarse ( } 2 \text { yr), } \\
\text { neck mass }\end{array}$ & $\begin{array}{l}\text { Subcutaneous } \\
\text { tissue }\end{array}$ & $20 \times 15 \times 10(\mathrm{P})$ & $\begin{array}{l}\text { Moderately well } \\
\text { differentiated (II). }\end{array}$ & PL & Unknown \\
\hline $\begin{array}{c}\text { Pareja Martínez, et al. (1989) } \\
{[40]}\end{array}$ & $55 \mathrm{M}$ & Neck mass (yrs) & Strap muscles & & Grade I & PL & Unknown \\
\hline Burggraaff, et al. (1992) [41] & $76 \mathrm{M}$ & $\begin{array}{c}\text { Neck mass, } \\
\text { dysphagia, } \\
\text { hoarseness ( } 2 \text { mo })\end{array}$ & $\begin{array}{l}\text { Adjacent } \\
\text { structures }\end{array}$ & $30 \times 50(\mathrm{PE})$ & Grade II & PL & Unknown \\
\hline Brandwein, et al. (1992) [26] & $69 \mathrm{M}$ & Not known & Cricoid & $35(\mathrm{P})$ & Grade I & PL-TL & Unknown \\
\hline Brandwein, et al. (1992) [26] & $73 \mathrm{M}$ & Voice change & Cricoid & $60(\mathrm{P})$ & Grade I-II & TL & NED (57) \\
\hline Brandwein, et al. (1992) [26] & $67 \mathrm{M}$ & Neck mass & & $50(\mathrm{P})$ & Grade I-II & PL-TL & Unknown \\
\hline Brandwein, et al. (1992) [26] & $52 \mathrm{~F}$ & Neck mass & Cricoid & $50(\mathrm{P})$ & Grade I & PL & NED (144) \\
\hline Brandwein, et al. (1992) [26] & $45 \mathrm{M}$ & Neck mass & & $35(\mathrm{P})$ & Grade I & PL & NED (38) \\
\hline Moran, et al. (1993) [42] & $70 \mathrm{~F}$ & $\begin{array}{l}\text { Hoarseness, } \\
\text { dysphagia } \\
\text { (several mo) }\end{array}$ & & $25(\mathrm{P})$ & Well-differentiated & PL & NED (48) \\
\hline Moran, et al. (1993) [42] & $75 \mathrm{M}$ & $\begin{array}{l}\text { Hoarseness, } \\
\text { dysphagia } \\
\text { (several mo) }\end{array}$ & & $30(\mathrm{P})$ & Well-differentiated & TL & NED (72) \\
\hline Wippold, et al. (1993) [32] & $77 \mathrm{M}$ & Neck mass (we) & & & Low grade (II) & Unknown & Unknown \\
\hline $\begin{array}{l}\text { Damborenea, } \\
\text { et al. (1999) [43] }\end{array}$ & $73 \mathrm{M}$ & $\begin{array}{c}\text { Neck mass, } \\
\text { hoarseness ( } 2 \text { we) }\end{array}$ & $\begin{array}{l}\text { Cricoid, } \\
\text { Aritenoid }\end{array}$ & & High grade & TL & NED (60) \\
\hline Faquin, et al. (2000) [44] & $74 \mathrm{M}$ & $\begin{array}{c}\text { Neck mass } \\
\text { (rapidly enlarging) }\end{array}$ & Strap muscles & $\begin{array}{l}45 \times 27 \times 10 \\
(\mathrm{CT})(\mathrm{P})\end{array}$ & $\begin{array}{l}\text { Low grade } \\
\text { (I) + Sarcoma }\end{array}$ & $\mathrm{TL}+\mathrm{RT}$ & Unknown \\
\hline Sakai, et al. (2000) [14] & $74 \mathrm{M}$ & $\begin{array}{c}\text { Neck mass } \\
\text { (Slowly growing) }\end{array}$ & Strap muscles & $45(\mathrm{CT})$ & $\begin{array}{c}\text { Low grade } \\
\text { Grade I-II + Sarcoma }\end{array}$ & PL-TL & Unknown \\
\hline Tomé, et al. (2001) [15] & $40 \mathrm{M}^{\mathrm{l}}$ & $\begin{array}{c}\text { Hoarseness (10-yr), } \\
\text { neck mass (2-yr) }\end{array}$ & & $60(\mathrm{P})$ & Low grade & TL & NED (336) \\
\hline Uygur, et al. (2001) [45] & $77 \mathrm{M}$ & $\begin{array}{l}\text { Neck mass (15 yr), } \\
\text { Pain (2 mo) }\end{array}$ & & $70 \times 60(\mathrm{PE})$ & Grade II & PL & NED (8) \\
\hline Jones, et al. (2003) [46] & $58 \mathrm{M}$ & Hoarseness & $\begin{array}{l}\text { Cricoid, } \\
\text { Aritenoid }\end{array}$ & $35(\mathrm{P})$ & Grade I-II & TL & NED (66) \\
\hline Jones, et al. (2003) [46] & $64 \mathrm{M}$ & Neck mass & $\begin{array}{l}\text { Cricoid, } \\
\text { periostoma }\end{array}$ & $35(\mathrm{P})$ & Grade I-II & TL & NED (47) \\
\hline Jones, et al. (2003) [46] & $72 \mathrm{M}$ & Hoarseness & (Lung) & $70(\mathrm{P})$ & Grade II-III & $\mathrm{TL}+\mathrm{RT}$ & DOD (12) \\
\hline Rinagio, et al. (2004) [47] & $60 \mathrm{M}$ & $\begin{array}{l}\text { Hoarseness (2 yr), } \\
\text { Dyspnea (3 mo) }\end{array}$ & $\begin{array}{l}\text { Strap muscles } \\
\text { (Lung) }\end{array}$ & $45 \times 25 \times 20(\mathrm{P})$ & Low grade + Sarcoma & $\mathrm{TL}+\mathrm{RT}$ & DOD (6.5) \\
\hline Casiraghi, et al. (2004) [16] & $69 \mathrm{M}$ & Hoarseness & & & Low grade & $\mathrm{TL}$ & NED (156) \\
\hline Casiraghi, et al. (2004) [16] & $43 \mathrm{M}$ & Neck mass & & & Low grade & PL & NED (264) \\
\hline Casiraghi, et al. (2004) [16] & $57 \mathrm{M}$ & Neck mass & & & Grade II & TL & NED (120) \\
\hline Casiraghi, et al. (2004) [16] & $53 \mathrm{M}$ & Hoarseness & & & Low grade & PL & NED (144) \\
\hline Lee, et al. (2005) [24] & $60 \mathrm{M}$ & Neck mass & (Tonsil) & & Grade II & $\mathrm{PL}+\mathrm{RT}$ & DOD (54) \\
\hline Pino Rivero, et al. (2006) [48] & $53 \mathrm{M}$ & Neck mass (yr) & & $30 \times 20(\mathrm{CT})(\mathrm{P})$ & Grade I & PL & NED (60) \\
\hline Moerman, et al. (2009) [49] & $64 \mathrm{M}$ & Neck mass (yr) & & $27 \times 20(\mathrm{CT})$ & Low grade & PL & Unknown \\
\hline Nao, et al. (2011) [50] & $63 \mathrm{M}$ & Neck mass & & $20(\mathrm{CT})$ & Grade I & PL & NED (48) \\
\hline Present case & $63 \mathrm{M}$ & Neck mass & Strap muscles & $18(\mathrm{CT})(\mathrm{P})$ & Grade II & PL & NED (51) \\
\hline
\end{tabular}

M, male; F, female; yr, years; mo, months; we, weeks; PE, Phisical exploration; P, pathology; CT, computed tomography scan; TL, total laryngectomy; PL, Partial laryngectomy; RT, Radiation therapy; DOD, died of disease; NED, no evidence of disease. 
Patient ages ranged from 40 to 77 years, (mean age 62 years) with a standard deviation (SD) of 11.2 years. The disease was more frequent in males (n: $31,88.6 \%$ ). The main symptoms were neck mass and hoarseness. The main location of the thyroid cartilage chondrosarcoma was the right thyroid lamina, although the exact location was not specified in many reports. In $57.2 \%$ of patients, the tumor size was evaluated by pathology and CT, with a range of 8.6 - $40 \mathrm{~mm}$. In $34.3 \%$ of cases, the tumor size was not stated. Tumors were mainly grade I and II (Table 1).

A total of 13 cases described tumor extension beyond the thyroid cartilage, with the cricoid cartilage and prelaryngeal muscles being the most common sitses. Among these 13 patients, 2 died from the disease (DOD) (1 with sarcoma), 5 with no evidence of disease (NED), and 6 patients had no reported follow-up (2 with sarcoma). All the patients with sarcoma showed strap muscle involvement (Table 1).

The main treatment used was partial laryngectomy in $50 \%$ of the patients $(n=17)$, and total laryngectomy in $26 \%(n=9)$. The treatment received was not specified in 1 patient (Table 2). Follow-up was documented in $74.3 \%$ of patients, with $84.6 \%$ being free of disease but $15.4 \%$ died (Table 1). Metastases were reported in 4 cases, 3 in the lung and 1 case in the tonsil.

When comparing the NED and DOD patients, it was observed that the mean age of those who died was $66.5 \pm$ 7.5, and those free of disease was $58.8 \pm 11.7$, however this difference was not statistically significant. All patients who died were male and had grade II and II-III tumors or associated sarcoma. In the NED group there were 16 males and 4 females, 16 patients had grade I, I-II tumors, 3 patients grade II and 1 patient grade III. There was no follow-up specified in 7 patients with tumors between grade I and II, and in 2 patients with associated sarcoma (Table 3).

Patients who died presented larger tumors than those who were disease free ( $57.5 \pm 17.6$ vs $39.8 \pm 18.5$ ), however these data are not statistically significant. No statistically significant association was found between clinical status, clinical presentation or tumor location. No statistically significant association was found between tumor size and histological grade. All those that died had metastases and received total laryngectomy (TL) and radiation therapy (RT). None of the NED patient had metastases, 13 patients were treated by partial laryngectomy (PL), and 8 patients by TL. One case required TL after PL.

\section{Discussion}

In thyroid chondrosarcoma there is a male predilection (9:1) similar to laryngeal chondrosarcoma (5-10:1) [22]

Table 2. Treatment in patients with thyroid cartilage chondrosarcoma.

\begin{tabular}{ccccc}
\hline Treatment & NED & DOD & Unknown & Total \\
\hline PL & 13 & 0 & 4 & $17(50 \%)$ \\
TL & 8 & 0 & 1 & $9(26 \%)$ \\
PL and posterior TL & 1 & 0 & 2 & $3(9 \%)$ \\
TL/PL + RT & 0 & 4 & 1 & $5(15 \%)$ \\
Total & 22 & 4 & 8 & 34 \\
\hline
\end{tabular}

NED, no evidence of disease; DOD, died of disease; PL, partial laryngectomy; TL, total laryngectomy.

Table 3. Evolution of the patients according to the thyroid cartilage chondrosarcoma tumor grade.

\begin{tabular}{cccc}
\hline Tumor grade & NED & DOD & Unknown \\
\hline I & 13 & & 3 \\
I-II & 3 & 2 & 3 \\
II & 3 & 1 & \\
II-III & 1 & 1 & 2 \\
III & & 1 & 2 \\
Sarcoma & & & \\
\hline
\end{tabular}

NED, no evidence of disease; DOD, died of disease. 
with the same age range $\left(4^{\text {th }}-7^{\text {th }}\right.$ decades) [23]. The main symptoms were neck mass and hoarseness similar to laryngeal chondrosarcoma.

Surgical treatment is known to be the most effective treatment modality. In low grade chondrosarcomas, conservation surgery ensuring complete tumor resection, which includes a margin of normal cartilage, is recommended [6] [34]. Total laryngectomy is reserved for large primary tumors or recurrence when complete resection by partial laryngectomy is not feasible [19] [25] [34]-[36]. There is no added survival benefit with total instead of partial laryngectomy. The main treatment in thyroid chondrosarcoma was PL, with a good prognosis in all except 4 patients, who in 2 cases required subsequent TL due to recurrence, however this was not specified in the other cases. The majority of patients who underwent TL had laryngeal, especially cricoid, cartilage extension. Considering the rare involvement of cervical lymph nodes, radical neck dissection is not routinely performed and must be reserved for cases in which the clinical picture suggests lymph node metastases. Tumor-free margins did not represent a guarantee that recurrence would not take place. These data should always be taken into consideration by the surgeon when conducting long-term follow-up [15].

Radiotherapy should be used for palliative purpose in unresectable cases, or as an adjuvant therapy in cases of residual disease [37]. In our review, 5 patients had RT as adjuvant therapy, 4 of them had metastases and died, and 1 patient had associated sarcoma without follow-up. Chemotherapy can be applied as an adjuvant therapy in high grade mesenchymal chondrosarcomas [4]. In our review, no patients received chemotherapy.

The prognostic factors are tumor grade and primary site, with resectability being the most important prognostic factor for some authors [24]. In our review we found that the most important prognostic factor was tumor grade. All patients with grade I and I-II survived, and all who died were grade II and II-III, or had sarcoma associated. The dedifferentiated variant is known for its poor prognosis. No statistically significant association was seen between tumor size and histological grade as previously proposed. Although there are differences between NED and DOD patients with respect to age and tumor size, these differences are not statistically significant. Although it has been proposed that the most common cause of death is local recurrence, and not metastasis [24], this review found that all patients with metastases died, with the metastases or its complications being the cause of death, and 2 patients with local recurrence survived.

\section{Conclusions}

- The main location of thyroid cartilage chondrosarcoma is the right ala of the thyroid. The principal symptom is neck mass. The average age at diagnosis is 62 years of age (40 - 77 years), and it is more common in men than women (9:1).

- Patients' clinical symptoms at the time of diagnosis do not correlate with tumor extension or prognosis.

- Patient age and tumor size does not influence the prognosis, although patients with a worse prognosis were older and had larger tumors.

- Patients with grade I and I-II tumors have good prognosis. Patients with tumors between grade II and III have unpredictable prognoses. Patients with associated sarcoma have a worse prognosis.

- Care must be taken with patients with strap muscle involvement because they may have an associated sarcoma.

- Patients with metastases have a poor prognosis.

- Partial laryngectomy is a good therapeutic option, although sometimes a total laryngectomy is required to ensure complete resection. There is no added survival benefit with total instead of partial laryngectomy.

- Radiotherapy has not demonstrated improved survival.

\section{References}

[1] Fechner, R.E. and Mills, S.E. (1993) Tumors of Bones and Joints. Atlas of Tumor Pathology, Fascicle, Vol. 8, 3rd Series, Armed Forces Institute of Pathology, Washington DC.

[2] Barnes, R. and Catto, M. (1996) Chondrosarcoma of Bone. The Journal of Bone \& Joint Surgery, 48, 729-764.

[3] Dofman, H.D. and Czerniak, B. (1995) Bone Cancers. Cancer, 75, 203-210. http://dx.doi.org/10.1002/1097-0142(19950101)75:1+<203::AID-CNCR2820751308>3.0.CO;2-V

[4] Ruark, D.S., Schlehaider, U.K. and Shah, J.P. (1992) Chondrosarcomas of the Head and Neck. World Journal of Surgery, 16, 1010-1016. http://dx.doi.org/10.1007/BF02067021

[5] Garrington, G.E. and Collet, W.K. (1988) Chondrosarcoma I. Literature Review. Journal of Oral Pathology \& Med- 
icine, 17, 1-11. http://dx.doi.org/10.1111/j.1600-0714.1988.tb01497.x

[6] Koch, B.B., Karnell, L.H., Hoffman, H.T., Apostolakis, L.W., Robinson, R.A., Zhen, W., et al. (2000) National Cancer Database Report on Chondrosarcoma of the Head and Neck. Head \& Neck, 22, 408-425. http://dx.doi.org/10.1002/1097-0347(200007)22:4<408::AID-HED15>3.0.CO;2-H

[7] Burkey, B.B., Hoffman, H.T., Baker, S.R., Thornton, A.F. and McClatchey, K.D. (1990) Chondrosarcoma of the Head and Neck. Laryngoscope, 100, 1301-1305. http://dx.doi.org/10.1288/00005537-199012000-00010

[8] Weiss, W.W. and Bennet, J.A. (1986) Chondrosarcoma: A Rare Tumor of the Jaws. Journal of Oral and Maxillofacial Surgery, 44, 73-79. http://dx.doi.org/10.1016/0278-2391(86)90017-0

[9] Gorenstein, A., Neel, H.B., Weiland, L.H. and Devine, K.D. (1980) Sarcomas of the Larynx. Archives of Otolaryngology, 106, 8-12. http://dx.doi.org/10.1001/archotol.1980.00790250010003

[10] Ferlito, A., Nicolai, P., Montaguti, A., Cecchetto, A. and Pennelli, N. (1984) Chondrosarcoma of the Larynx: Review of the Literature and Report of Three Cases. American Journal of Otolaryngology, 5, 350-359. http://dx.doi.org/10.1016/S0196-0709(84)80005-8

[11] Batsakis, J.G. and Raumond, A.K. (1988) Cartilage Tumors of the Larynx. Southern Medical Journal, 81, $481-484$. http://dx.doi.org/10.1097/00007611-198804000-00018

[12] Palacios, E. and Valvassori, G. (1988) Chondrosarcoma of the Larynx. Ear, Nose \& Throat Journal, 77, 951.

[13] Thompson, L.D.R. and Gannon, F.H. (2002) Chondrosarcoma of the Larynx: A Clinicopathologic Study of 111 Cases with a Review of the Literature. The American Journal of Surgical Pathology, 26, 836-851. http://dx.doi.org/10.1097/00000478-200207000-00002

[14] Sakai, O., Curtin, H.D., Faquin, W.C. and Fabian, R.L. (2000) Dedifferentiated Chondrosarcoma of the Larynx. AJNR American Journal of Neuroradiology, 21, 584-586.

[15] Tomé, R., Thomé, D.C. and de la Cortina, R.A. (2001) Long-Term Follow-Up Cartilaginous Tumors of the Larynx. Otolaryngology—Head and Neck Surgery, 124, 634-640. http://dx.doi.org/10.1067/mhn.2001.116183

[16] Casiraghi, O., Martinez-Madrigal, F., Pineda-Daboin, K., Mamelle, G., Resta, L. and Luna, M.A. (2004) Chondroid Tumors of the Larynx: A Clinicopathologic Study of 19 Cases, Including Two Dedifferentiated Chondrosarcomas. Annals of Diagnostic Pathology, 8, 189-197. http://dx.doi.org/10.1053/j.anndiagpath.2004.04.001

[17] Hately, W., Evison, G. and Samuel, E. (1965) The Pattern of Ossification in the Laryngeal Cartilages: A Radiological Study. The British Journal of Radiology, 38, 585-591. http://dx.doi.org/10.1259/0007-1285-38-452-585

[18] Harrison, D.F.N. and Denny, S. (1983) Ossification within the Primate Larynx. Acta Oto-Laryngologica (Stockholm), 95, 440-446. http://dx.doi.org/10.3109/00016488309139427

[19] Neis, P.R., McMahon, M.F. and Morris, C.W. (1989) Cartilaginous Tumors of the Trachea and Larynx. Annals of Otology, Rhinology, and Laryngology, 98, 31-36.

[20] Busuttil, A. and Forbes, J. (1978) Chondrosarcomas of the Thyroid Cartilage. The Journal of Laryngology \& Otology, 92, 633-638. http://dx.doi.org/10.1017/S002221510008587X

[21] Östberg, Y., Boquis, L. and Diamant, H. (1979) Laryngeal Chondrosarcoma in Sweden. Acta Oto-Laryngologica (Stockholm), 88, 142-147. http://dx.doi.org/10.3109/00016487909137153

[22] Batsakis, J.G., Solomon, A.R. and Rice, D.H. (1980) The Pathology of Head and Neck Tumors: Neoplasm of Cartilage, Bone, and the Notochord, Part 7. Head and Neck Surgery, 3, 43-57. http://dx.doi.org/10.1002/hed.2890030110

[23] Arlen, M., Toleefsen, H.F., Huvos, A.G. and Marcove, R.C. (1970) Chondrosarcoma of Head and Neck. The American Journal of Surgery, 120, 456-460. http://dx.doi.org/10.1016/S0002-9610(70)80006-X

[24] Lee, S.Y., Lim, Y.C., Song, M.H., Seok, J.Y., Lee, W.S. and Choi, E.C. (2005) Chondrosarcoma of the Head and Neck. Yonsei Medical Journal, 46, 228-232. http://dx.doi.org/10.3349/ymj.2005.46.2.228

[25] Hyams, V.J. and Rabuzzi, D.D. (1970) Cartilaginous Tumors of the Larynx. Laryngoscope, 80, 755-767. http://dx.doi.org/10.1288/00005537-197005000-00007

[26] Brandwein, M., Moore, S., Som, P. and Biller, H. (1992) Laryngeal Chondrosarcomas: A Clinicopathologic Study of 11 Cases, Including Two “Dedifferentiated” Chondrosarcomas. Laryngoscope, 102, 858-867. http://dx.doi.org/10.1288/00005537-199208000-00004

[27] P. Nicolai, A. Ferlito, C.T. Sasaki, J.A. Kirchner (1990) Laryngeal Chondrosarcoma: Incidence, Pathology, Biological Behavior, and Treatment. Annals of Otology, Rhinology, and Laryngology, 99, 515-523.

[28] Evans, H.L., Ayala, A.G. and Romsdahl, M.M. (1977) Prognostic Factors in Chondrosarcoma of Bone. Cancer, 40, 818-831. http://dx.doi.org/10.1002/1097-0142(197708)40:2<818::AID-CNCR2820400234>3.0.CO;2-B

[29] Bleiweiss, I. and Kancko, M. (1988) Chondrosarcoma of the Larynx with Additional Mesenchymal Component (DeDifferentiated Chondrosarcoma). The American Journal of Surgical Pathology, 12, 314-320. 
http://dx.doi.org/10.1097/00000478-198804000-00009

[30] Frassica, F., Unni, K., Beabout, J. and Sim, F. (1986) Dedifferentiated Chondrosarcoma: A Report of the Clinicopathological Features and Treatment of Seventy-Eight Cases. The Journal of Bone \& Joint Surgery, 68, 1197-1205.

[31] Johnson, S., Tetu, B., Ayala, A. and Chawla, S. (1986) Chondrosarcoma with Additional Mesenchymal Component (De-Differentiated Chondrosarcoma): 1: A Clinicopathologic Study of 26 Cases. Cancer, 58, 278-286. http://dx.doi.org/10.1002/1097-0142(19860715)58:2<278::AID-CNCR2820580213>3.0.CO;2-6

[32] Wippold, F.J., Smirniotopoulos, J.G., Moran, C.J. and Glazer, H.S. (1993) Chondrosarcoma of the Larynx: CT Features. AJNR American Journal of Neuroradiology, 14, 453-459.

[33] Mishell, J.H., Schild, J.A. and Mafee, M.F. (1991) Chondrosarcoma of the Larynx: Diagnosis with Magnetic Resonance Imaging and Computed Tomography. Archives of Otolaryngology—Head and Neck Surgery, 116, 1338-1341. http://dx.doi.org/10.1001/archotol.1990.01870110110016

[34] Lewis, J.F., Olsen, K.D. and Inwards, C.Y. (1997) Cartilaginous Tumors of the Larynx: Clinicopathologic Review of 47 Cases. Annals of Otology, Rhinology, and Laryngology, 106, 94-100.

[35] Huizenga, C. and Balogh, K. (1970) Cartilaginous Tumors of the Larynx: A Clinicopathologic Study of 10 New Cases and a Review of the Literature. Cancer, 26, 201-210. http://dx.doi.org/10.1002/1097-0142(197007)26:1<201::AID-CNCR2820260126>3.0.CO;2-S

[36] Lavertu, P. and Tucker, H.M. (1984) Chondrosarcoma of the Larynx: Case Report and Management Philosophy. Annals of Otology, Rhinology, and Laryngology, 93, 452-456.

[37] Harwood, A.R., Krajbich, J.I. and Fornasier, V.L. (1980) Radiotherapy of Chondrosarcoma of Bone. Cancer, 45, 27692777. http://dx.doi.org/10.1002/1097-0142(19800601)45:11<2769::AID-CNCR2820451111>3.0.CO;2-X

[38] Finn, D.G., Goepfert, H. and Batsakis, J.G. (1984) Chondrosarcoma of Head and Neck. Laryngoscope, 94, $1539-1544$. http://dx.doi.org/10.1288/00005537-198412000-00001

[39] Van Holsbeeck, M.T., Stessens, R.C., Oyen, R.H., Wilms, G.E. and Baert, A.L. (1985) CT Diagnosis of Larynx Chondrosarcoma. European Journal of Radiology, 5, 297-299.

[40] Pareja Martinez, A., Alberola Toriol, V., Severa Ferrandiz, G. and Infante Matarredonda, E. (1989) Condrosarcoma de Cartilago Tiroides. Presentación de un Caso y Revisión de la Literatura. Acta Otorrinolaringológica Española, 40, 373-376.

[41] Burggraaff, B.A. and Weinstein, G.S. (1992) Chondrosarcoma of the Larynx. Annals of Otology, Rhinology, and Laryngology, 101, 183-184.

[42] Moran, C.A., Suster, S. and Carter, D. (1993) Laryngeal Chondrosarcomas. Archives of Pathology \& Laboratory Medicine, 117, 914-917.

[43] Damborenea Tajada, J., Campos del Alamo, M.A., Llorente Arenas, E., Naya Galvez, M.J., Castillo Fornies, A.C. and Fernandez Liesa, R. (1999) Our Experience in Chondrosarcoma. Three Case Reports. Anales Otorrinolaringológicos Ibero-Americanos, 26, 241-248.

[44] Faquin, W.C., Pilch, B.Z., Keel, S.B. and Cooper, T.L. (2000) Fine-Needle Aspiration of Dedifferentiated Chondrosarcoma of the Larynx. Diagnostic Cytopathology, 22, 288-292. http://dx.doi.org/10.1002/(SICI)1097-0339(200005)22:5<288::AID-DC6>3.0.CO;2-F

[45] Uygur, K., Tüz, M., Dogru, H. and Sari, A. (2001) Chondrosarcoma of the Thyroid Cartilage. Journal of Laryngology \& Otology, 115, 507-509. http://dx.doi.org/10.1258/0022215011908081

[46] Jones, D.A., Dillard, S.C., Bradford, C.R., Wolf, G.T. and Prince, M.E. (2003) Cartilaginous Tumors of the Larynx. Journal of Otolaryngology, 32, 332-336. http://dx.doi.org/10.2310/7070.2003.11351

[47] Rinaggio, J., Duffey, D. and McGuff, H.S. (2004) Dedifferentiated Chondrosarcoma of the Larynx. Oral Surgery, Oral Medicine, Oral Pathology, Oral Radiology and Endodontology, 97, 369-375. http://dx.doi.org/10.1016/j.tripleo.2003.09.015

[48] Pino Rivero, V., Keituqwa Yañez, T., Gonzalez Palomino, A., Trinidad Ramos, G., Marques Rebollo, L., Gomez de Tejada Romero, R. and Blasco Huelva, A. (2006) Condrosarcoma Laringeo de Bajo Grado de Malignidad. Anales Otorrinolaringológicos Ibero-Americanos, 23, 249-256.

[49] Moerman, M., Kreps, B. and Forsyth, R. (2009) Laryngeal Chondrosarcoma: An Exceptional Localisation of a Not Unfrequent Bone Tumor. Sarcoma, 2009, Article ID: 394908. http://dx.doi.org/10.1155/2009/394908

[50] Nao, E.E., Bozec, A., Vallicioni, J., Poissonnet, G., Riss, J.C., Agopian, B., Pierrea, C.S., Sudakab, A., Demarda, F., Santinia, J. and Dassonville, O. (2011) Laryngeal Chondrosarcoma: Report of Two Cases. European Annals of Otorhinolaryngology, Head and Neck Diseases, 128, 191-193. http://dx.doi.org/10.1016/j.anorl.2011.02.001 